Research Article

\title{
Seismic Vulnerability Analysis of Rural Modified Raw-Soil Structures
}

\author{
Shiwei Hou, Hao Zhang (iD, Yuzhe Zhang, Xin Chen, and Suyun Meng
}

School of Civil Engineering, Shenyang Jianzhu University, Liaoning 110168, China

Correspondence should be addressed to Hao Zhang; h_zhang@sjzu.edu.cn

Received 17 June 2021; Revised 24 July 2021; Accepted 10 August 2021; Published 18 August 2021

Academic Editor: Piguang Wang

Copyright ( $\odot 2021$ Shiwei Hou et al. This is an open access article distributed under the Creative Commons Attribution License, which permits unrestricted use, distribution, and reproduction in any medium, provided the original work is properly cited.

\begin{abstract}
Based on the concept of environmental protection of solid waste utilization, material testing is conducted to achieve native improvement using coal gangue-based limestone-calcined clay cement (LC3). Finite element (FE) models of rural raw-soil architecture with a colored-steel roof (RACSR) were established. The effect of modified soil type and seismic character on the vulnerability of single-story raw-soil structures was investigated using probabilistic seismic demand (PSD) analysis. The seismic response characteristics of 80 representative sequences were comparatively investigated when subjected to northwest clay (raw soil) of China, fiber and stone-improved clay (modified soil), and coal gangue-based limestone-calcined clay cement (LC3 soil). The maximum interstory drift angle (ISDA $A_{\max }$ ) was lower in the LC3 soil model and the modified soil model compared to the rawsoil model. The use of LC3 soil improves structural resistance and reduces the damage probability of a structure, and the influence of different ultimate failure states on the vulnerability of the raw-soil structure was studied.
\end{abstract}

\section{Introduction}

Earthquakes are natural catastrophes that severely impact society owing to the associated loss of life and damage to building facilities. To date, most studies have focused on performance-based seismic design and risk assessment, and research on seismic vulnerability has primarily considered steel, concrete, and masonry structures. It is necessary to study the seismic vulnerability of rural buildings as part of earthquake disaster loss assessment and structural reinforcement. Raw-soil structures are local material, facilitate simple construction, have low cost, are warm in winter and cool in summer, and promote energy saving and environmental protection. They are still widely used in rural areas of China, especially in economically underdeveloped regions [1]. However, owing to the poor ductility, shear resistance, and bending strength of rural buildings, if coupled with injudicious site selection, poor foundation treatment, poor quality masonry, and planning and layout defects, the degree of seismic damage is much higher compared to that of other structures [2].
To reduce the casualties and damage associated with seismic events, numerous studies on the antiseismic performance of raw-soil structures have been conducted. The emphasis has been on structural construction measures and the improvements of raw-soil material. Miccoli et al. [3] conducted tests of rammed Earth walls strengthened with polyester fabric strips and discussed the effect of cyclic loading. Ma et al. [4] investigated adobe masonry strengthened with ferrocement mortar based on theoretical analysis, experimental research, and finite element simulation and found that the failure mode is a shear failure and shear-compression failure. Klingner et al. [5] conducted a static pushover test of an adobe house strengthened with a wooden frame. The results showed that the integrity and bearing capacity can be effectively improved. Based on the investigation and analysis of the earthquake damage mechanism of raw-soil buildings, Pavan et al. [6] analyzed the interfacial behavior of cement-stabilized rammed Earth. Zhou et al. [7] conducted a shaking table test and analyzed the scale model of two types of adobe house reinforcement modes. The results showed that the proposed plaster-adobewall structure and the wooden-frame-adobe-wall structure 
could resist earthquakes of magnitude $8.0 . \mathrm{Bu}$ et al. [8] proposed a mixed raw-soil structure and conducted a static test and finite element simulation on the wall opening. The results showed that the raw-soil-mixed wall can effectively address the brittle failure of traditional raw-soil walls during earthquakes, and the opening rate of the wall had a significant impact on the seismic performance. Bui et al. [9] focused on the antiseismic design parameters of raw-soil structures and proposed a formula for seismic calculations. According to the experimental and numerical assessment, Li et al. [10] investigated effective antiseismic measures that can be applied to adobe walls. Chen et al. [11] analyzed raw-soil building performance and damage associated with the Nepal earthquake. Illampas et al. [12] analyzed the influence of horizontal loading on the performance of adobe masonry building by laboratory testing and FE simulation. Ghasemalizadeh and Toufigh [13] conducted an experimental study on the durability of rammed building walls and explored the modification of ram soil materials. Tripura and Singh [14] discussed the mechanical behavior of columns reinforced with steel and bamboo. Tripura et al. [15] further discussed the flexural strength and failure trend of bamboo and coir reinforced cement-stabilized rammed Earth wallets. An efficacious design and construction system for raw-soil structures is not currently available, and many self-built houses lack corresponding structural measures, which will significantly affect the seismic performance of raw-soil structures. Research on raw-soil materials mainly focuses on standardized production processes, structural construction measures, and methods to improve raw-soil materials. Structural construction measures are implemented to improve the overall stability and rigidity of the raw-soil structure. However, studies on the improvement of raw-soil materials have mainly focused on local materials and solid waste utilization, such as the use of natural fibers and life/ industrial waste to improve the raw soil. Therefore, it is necessary to further improve the theoretical basis of seismic design and risk assessment methods for raw-soil structures.

Seismic vulnerability refers to the possible different failure states of engineering structures under different earthquake intensities, which are used for pre- and postearthquake loss assessments. Seismic vulnerability analysis was first used to evaluate the seismic performance of important structures such as nuclear power plants. With the increase of property losses in casualties as earthquake damage to buildings, seismic vulnerability research has been gradually applied to the evaluation of the seismic performance of common engineering structures. From the perspective of area-wide estimation, An et al. [16] redefined the seismic vulnerability analysis based on the decision tree method. Zhao et al. [17] established 18 structural models of village and town buildings according to the three categories of rural, town, and county and obtained the corresponding vulnerability curves to evaluate the rationality of the three levels of fortification standards. Li et al. [18] discussed the seismic vulnerability and spatial distribution of native soil buildings in western China and proposed a multidimensional information acquisition survey method. He et al. [19] conducted a statistical analysis of the damage and economic losses caused by 80 earthquake disasters in Yunnan Province from 1993 to 2015 and obtained vulnerability curves for different seismic intensities and building structures. Considering the damage samples of buildings in the Wenchuan earthquake area, Sun and Zhang [20] analyzed the seismic damage characteristics of typical structures and performed seismic vulnerability analysis and seismic capacity studies. The results showed that the masonry structure was the most seriously damaged among the buildings in the Wenchuan earthquake-stricken areas. Based on the incremental dynamic analysis (IDA) collapse vulnerability method, Ren et al. [21] compared and discussed the influence of the magnitude, epicentral distance, site conditions, and other ground motion parameters associated with earthquakes on the structural vulnerability curve of three different structures. Lourenço and Roque [22] proposed a seismic vulnerability index for traditional masonry structures that included the statistical analysis of the data for 58 historical churches in Portugal. Lagomarsino and Giovinazzi [23] proposed two models and applied them to the analysis of different types of buildings to evaluate the vulnerability and to examine damage assessment, which can be applied to European towns and regions. Based on the equivalent frame method and SAP2000 software, Pasticier et al. [24] obtained seismic vulnerability curves for typical two-story masonry structures by linearly fitting the data generated from incremental dynamic analysis. Karbassi and Nollet [25] selected 14 synthetic and real ground motion records and utilized them in a 3D model of an unreinforced masonry structure based on the applied element method to analyze seismic vulnerability. The estimation model of horizontal aftershock ground motion in the active crustal region was developed by Byungmin and Moochul [26], which is a useful technique for the vulnerability analysis of raw-soil buildings. Giovanni and Claudio [27] investigated several methods and concluded that the influence of masonry structures under earthquake sequences is important as an engineering reference. Zhang et al. [28] established a transient seismic structure-water-sediment-rock (SWSR) interaction model and discussed its application. Wang et al. [29] obtained the dynamic resistance factor of the soil layer and proposed a substructure method for seismic responses that consider nonlinear pile-soil dynamic interactions. Pang et al. [30] proposed a uniform design- (UD-) based Gaussian process regression (GPR) method for rapid damage assessment and vulnerability estimates of bridges. Pang and Wang [31] presented an efficient method for converting vulnerability curves from the cloud to IDA and MSA and from IDA to MSA toward an efficient and high-fidelity resilience assessment.

However, there is a dearth of research on the vulnerability of raw-soil structures, which is critical for improving seismic design and seismic risk assessment methods of rawsoil structures. In particular, raw-soil structures in rural areas are typically not optimally designed, and many selfbuilt houses lack the necessary confining members; therefore, these raw-soil structures often exhibit inferior seismic performance. To address this problem, the seismic response characteristics and seismic vulnerability of raw-soil 
structures are investigated in rural areas of China, based on dynamic time history analysis and probabilistic seismic demand analysis. Considering a typical single-story raw-soil structure from a rural region in China as an example, finite element models of raw-soil architecture with a colored steel roof (RACSR) were established. Based on the Mw-R strip method, data for 80 real ground motions were selected for analysis. The seismic response characteristics of raw-soil structures under earthquake action were analyzed by considering the interstory drift angle (ISDA) as a seismic performance index. A probabilistic seismic demand model of the rural raw-soil structure was established, and the vulnerability curves were obtained under different working conditions. On this basis, the effects of different raw-soil improvement methods on the seismic response and fragility of raw-soil structures were rigorously investigated, and the influence of different limit failure states on the seismic vulnerability of rural raw-soil structures was also examined.

\section{The Modification of Raw-Soil Materials}

To improve raw-soil materials, the physical and mechanical defects of soil should be significantly enhanced by the appropriate selection of modification materials. It is difficult to promote high-cost programs in rural areas. Raw soil has been used as a building material because of its incomparable environmental protection. Therefore, the modification materials should be carefully chosen. If the selected materials negatively impact the ecological environment, this is contrary to the intent of the original project. Therefore, in the selection of modification materials, effectiveness, cost-effectiveness, and environmental protection are the basic criteria. Standardized production technology, mechanical construction method of structural components, and chemical and physical improvement methods of raw materials are the main areas of research of raw-soil structure design and construction, especially the use of natural fiber and domestic/industrial waste to improve the raw soil. Wang [32] added recycled starch, quicklime, and hydrated lime to the raw soil, which were used in raw soil in mountainous areas. The compression and shear properties of the modification materials were tested and analyzed, and the results showed that the recycled starch was suitable for addition to the original soil. Liu et al. [33] used red clay in northern Sichuan of China as raw-soil material, polypropylene fiber, and gravel as physical modification materials, and emulsion powder as a chemical dispersion modification material to test the composite improvement effect. Based on comparative studies of raw and modified soil [33], this study focused on limestone-calcined clay-cement-modified raw soil.

Limestone-calcined clay cement (LC3) is a novel ternary blend. It is a new type of cement made from calcined clay (30\%), limestone (15\%), and gypsum (5\%), instead of (50\%) clinker in traditional cement. Coal gangue is a type of waste generated in the production of coal mining and tunneling. Owing to its low calorific value and high ash, it is an industrial solid waste that is difficult to use. Coal gangue has a specific calorific value, contains a certain amount of silicon aluminum components, which is similar to clay, and can be used as an alternative raw material to clay. The annual global cement production is 4 billion tons. China accounts for $58.13 \%$ of the world's consumption. The production of $1 t$ of cement generates $0.82 t$ of carbon dioxide [34]. Therefore, the replacement of part of cement clinker with coal gangue can significantly reduce the carbon footprint in cement production. Coal gangue can partly or completely replace clay when improving and strengthening soil. If further sintered into bricks or lightweight aggregate, coal can be saved and the weight of buildings can be reduced by $20 \%$.

The cement used in experiments was coal gangue-based LC3, which was mixed in a laboratory with Portland cement clinker, coal gangue powder, limestone powder, and dehydrated gypsum in the proportion of $50: 30: 15: 5$. Portland cement clinker was made by grinding an undisturbed clinker ball using a ball mill for $1 \mathrm{~h}$, followed by filtering using a 200-mesh standard sieve, as shown in Figure 1(a). Coal gangue powder was calcined in an industrial furnace at $850^{\circ} \mathrm{C}$ and then filtered using a 200-mesh standard sieve, as shown in Figure 1(b). Limestone is white crystalline powders with a content $\left(\mathrm{CaCO}_{3}\right)$ of more than $99.0 \%$, which meets the requirements of the national standard of China. Dehydrated gypsum is white crystalline powders with a content $\left(\mathrm{CaSO}_{4} \cdot 2 \mathrm{H}_{2} \mathrm{O}\right)$ of more than $99.0 \%$, which meets the requirements of the national standard of China. The kaolin soil produced in the factory is shown in Figure 1(c). The chemical composition of each component is listed in Table 1. Kaoling soil has a specific gravity (Gs) of 2.71, a liquid limit $\left(W_{L}\right)$ of $36.6 \%$, a plastic limit $\left(W_{P}\right)$ of $21.2 \%$, a water content $(\omega)$ of $0.12 \%$, and a $\mathrm{pH}$ value of 7.83 .

A batch of coal gangue-based LC3 specimens with different cement contents and curing ages were prepared for mechanical and microstructural tests. First, the kaolin soil and the prepared coal gangue-based LC3 were fully mixed in proportion, the water content was maintained at $38 \%$, and a cement mortar mixer was used to perform uniform mixing. Second, the cement soil was added to the mold after mixing and then placed on a vibration table for compaction. The surface was scraped, covered with a layer of preservative film, and allowed to stand at $20 \pm 5^{\circ} \mathrm{C}$ for $48 \mathrm{~h}$. Finally, the samples were demolded, then placed in a self-sealing bag, and cured in water at $20 \pm 1^{\circ} \mathrm{C}$. The curing periods were $7 \mathrm{~d}$, $14 \mathrm{~d}, 28 \mathrm{~d}$, and $60 \mathrm{~d}$.

The unconfined compressive strength (UCS) test is an index that summarizes the engineering properties of cement-stabilized soil. This strength characteristic represents the ability to carry vertical loads under no side limit pressure conditions, and the results can be used to calculate mechanical parameters such as elastic modulus. The loading rate was controlled during the test, and the load was applied evenly to the specimens at $0.03-0.15 \mathrm{kN} / \mathrm{s}$ until damage occurred, and the failure load was recorded accurately to $\pm 0.01 \mathrm{kN}$. The UCS test of coal gangue-based LC 3 soil blocks $(70.7 \mathrm{~mm} \times 70.7 \mathrm{~mm} \times 70.7 \mathrm{~mm})$ with different cement contents $(5 \%, 10 \%, 15 \%$, and $20 \%)$ and curing ages $(7 \mathrm{~d}, 14 \mathrm{~d}$, $28 \mathrm{~d}$, and $60 \mathrm{~d}$ ) was performed. Figure 2 shows the test process and some LC3 soil sample failure modes. In this study, the test data at 28 days of curing and $5 \%$ content, which is similar to that of fiber-reinforced soil, were selected 


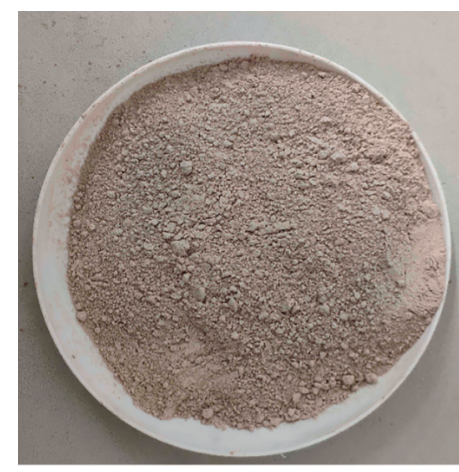

(a)

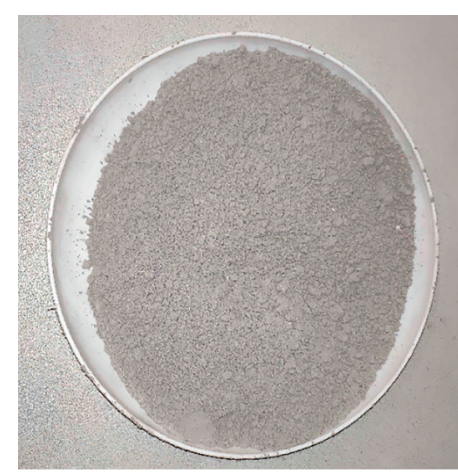

(b)

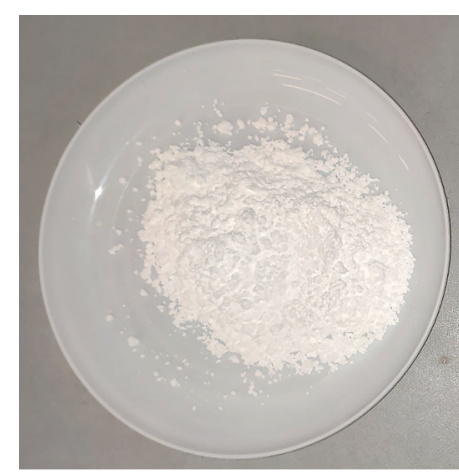

(c)

Figure 1: Limestone-calcined clay cement. (a) Cement clinker. (b) Coal gangue powder. (c) Kaolin soil.

TABle 1: Chemical composition of LC3.

\begin{tabular}{lccc}
\hline Composition & $\begin{array}{c}\text { Cement clinker } \\
(\%)\end{array}$ & $\begin{array}{c}\text { Kaolin soil } \\
(\%)\end{array}$ & Coal gangue (\%) \\
\hline $\mathrm{SiO}_{2}$ & 21.76 & $53 \pm 1$ & 50 \\
$\mathrm{Al}_{2} \mathrm{O}_{3}$ & 5.82 & $45 \pm 1$ & 47 \\
$\mathrm{Fe}_{2} \mathrm{O}_{3}$ & 3.38 & $\leq 0.3$ & 0.6 \\
$\mathrm{CaO}$ & 62.75 & $\leq 0.07$ & 0.3 \\
$\mathrm{MgO}$ & 1.71 & $\leq 0.06$ & 0.5 \\
$\mathrm{~K}_{2} \mathrm{O}$ & 1.20 & $\leq 0.05$ & 0.1 \\
$\mathrm{Na}_{2} \mathrm{O}$ & 0.07 & - & 0.2 \\
$\mathrm{SO}_{3}$ & 1.06 & - & - \\
$\mathrm{P}_{2} \mathrm{O}_{5}$ & 0.23 & - & - \\
$\mathrm{TiO}_{2}$ & - & $\leq 0.6$ & 1.5 \\
$\mathrm{MnO}_{\mathrm{LnO}}$ & - & $\leq 0.004$ & - \\
ignition & 1.05 & 0.4 & - \\
\hline
\end{tabular}

to analyze seismic vulnerability. The Australian Native Building Code HB 195 stipulates that the elastic modulus of native building materials should be higher than $200 \mathrm{MPa}$. The test results show that raw clay and modified and LC3 soil met this condition. When the LC3 content was 5\%, the cement strength satisfied the requirements of the standard project.

The microstructure of the cement soil was studied using scanning electron microscopy. The test block was broken after the UCS test, and several fragments were cut using a knife. The selected observation surface area was approximately $5 \mathrm{~mm} \times 5 \mathrm{~mm}$ and $3 \mathrm{~mm}$ thick and dried for standby. Before the test, the surface of the soil sample was coated with a thin layer of gold to increase its conductivity. To observe the overall structure and local microstructural changes of the test sample, the magnification of the SEM image was set at 1000 and 5000 times, respectively. Figure 3 shows that the particles of the LC3 soil have small pores that are evenly distributed and form dense lumps, making the sample uniform and dense.

\section{The Description of the Structural Models}

3.1. Finite Element Models of the Raw-Soil Structures. In the modeling scheme of the numerical simulation, a three-slot symmetrical layout of the raw-soil architecture with a colored-steel roof (RACSR) was utilized. As shown in Figure 4, the investigated raw-soil structures have a dimension of $13.9 \mathrm{~m} \times 6.4 \mathrm{~m}$. The axis of the bay was $4.5 \mathrm{~m} \times 6 \mathrm{~m}$, the height of the soil transverse wall was $4.28 \mathrm{~m}$, the height of the longitudinal wall was $3 \mathrm{~m}$, and the height of the back wall without a window was $3 \mathrm{~m}$. The roof truss was a symmetrical double-slope roof, which was used to bear the load of the ram soil cross-wall. The wall thickness of the model was $0.4 \mathrm{~m}$. Windows were present in the left and right rooms. The windowsill height was $0.9 \mathrm{~m}$ and the window size was $1.2 \mathrm{~m} \times 1.2 \mathrm{~m}$. The size of the entrance door was $1.5 \mathrm{~m} \times 2.1 \mathrm{~m}$, and the size of the room door was $1.2 \mathrm{~m} \times 2.1 \mathrm{~m}$. Finite element models of the raw-soil structures were established using the ABAQUS platform. The structures were simulated using solid elements. After many trial calculations, $200 \mathrm{~mm}$ grids were finally selected. The model and grid of the RACSR are shown in Figure 5.

3.2. Constitutive Model of Soil Material. The Mohr-Coulomb model is the most widely used constitutive model in geotechnical engineering. Figure 6(a) shows the Mohr-Coulomb yielding model, which expresses the state when the failure line of the Mohr-Coulomb criterion is tangent to the Mohr stress circle. The parameters $\sigma_{1}, \sigma_{2}$, and $\sigma_{3}$ are the maximum principal stress, medium principal stress, and minimum principal stress, respectively. The Mohr-Coulomb criterion can be expressed as follows:

$$
\begin{aligned}
\left(\frac{\tau}{\sigma}\right)_{\max } & =\tan \varphi \\
& =\frac{\sigma_{1}-\sigma_{3}}{2 \sqrt{\sigma_{1} \sigma_{3}}}=k .
\end{aligned}
$$

The classical expression that is used in soil mechanics is as follows:

$$
\tau_{f}=c+\sigma \cdot \tan \varphi,
$$

where $\tau$ is the shearing stress, $\sigma$ is the normal stress, $c$ is the cohesion, $\varphi$ is the internal friction angle of the soil, and $k$ is a constant.

It is expressed the form of the principal stress as follows: 


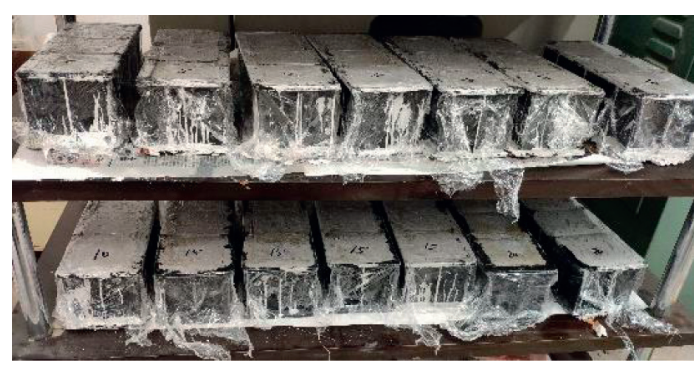

(a)

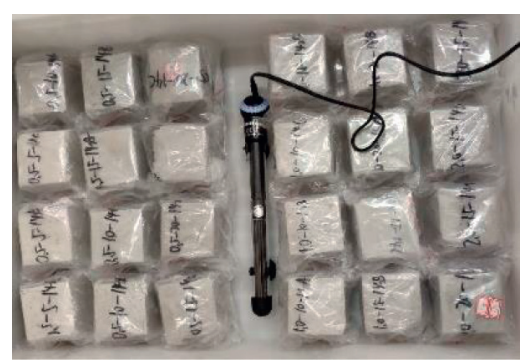

(b)

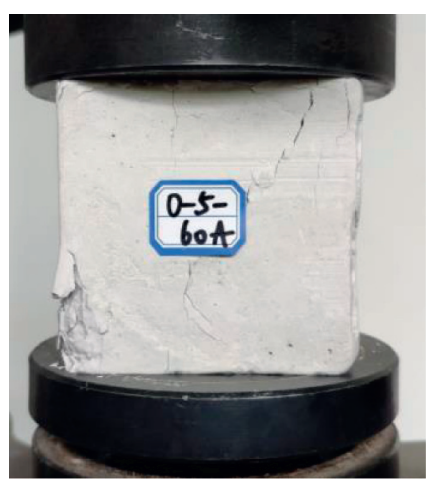

(c)

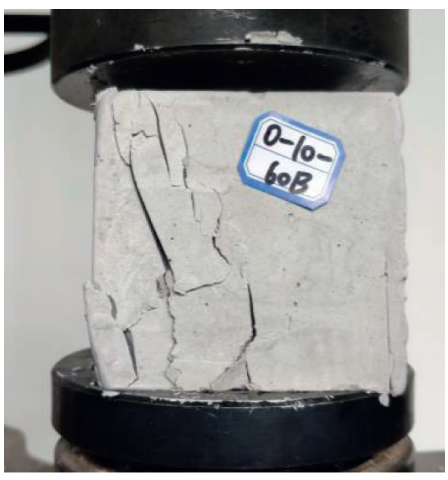

(d)

Figure 2: Unconfined compressive strength test. (a) Sample molding. (b) Demoulding curing. (c) Failure mode of 5\% LC3 cement block. (d) Failure mode of $10 \%$ cement block.

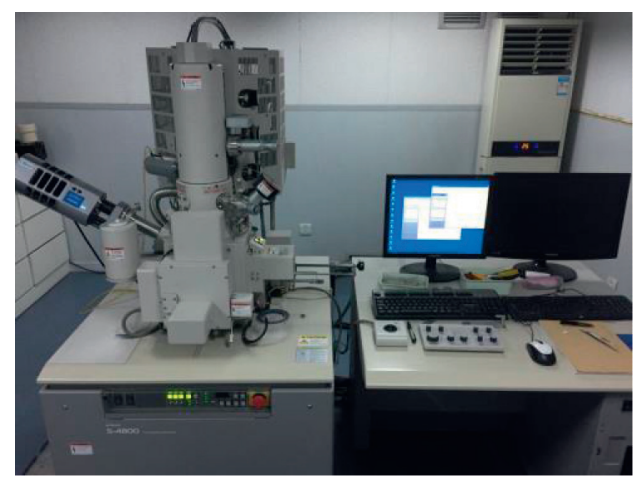

(a)

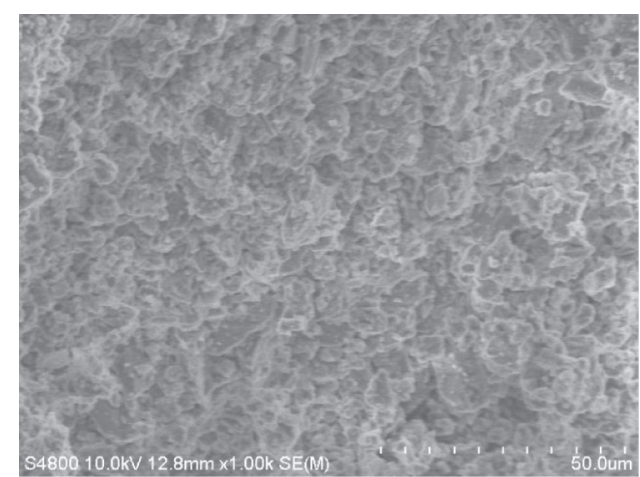

(b)

Figure 3: Cement soil microimage test. (a) Test apparatus. (b) LC3 soil microimage.

$$
\sigma_{1}(1-\sin \varphi)-\sigma_{3}(1+\sin \varphi)=2 c \cos \varphi
$$

The yield surface shapes of the three dimensions and the $\pi$-plane shape are shown in Figures 6(b) and 6(c), and the Mohr-Coulomb yield condition can be expressed as follows:

$$
F(\sigma)=\frac{1}{3} I_{1} \sin \varphi+\left(\cos \theta_{\sigma}-\frac{1}{\sqrt{3}} \sin \theta_{\sigma} \sin \varphi\right) \sqrt{J_{2}}-c \cos \varphi=0,
$$




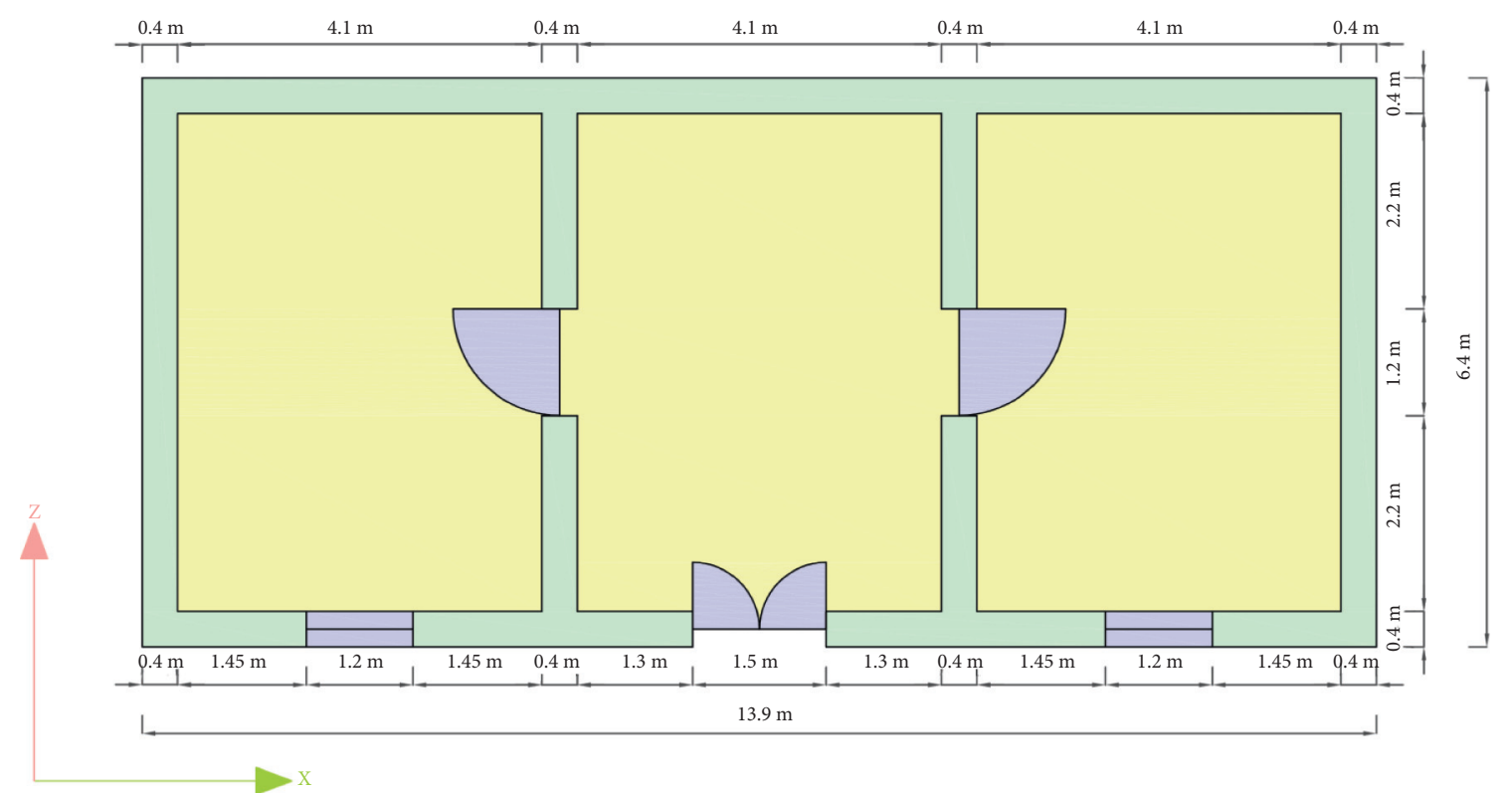

(a)

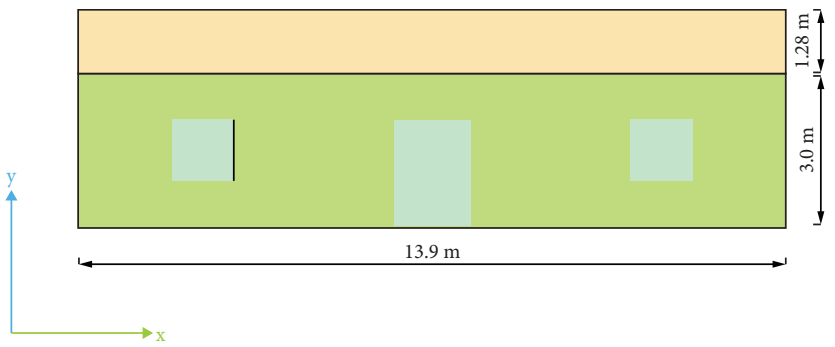

(b)

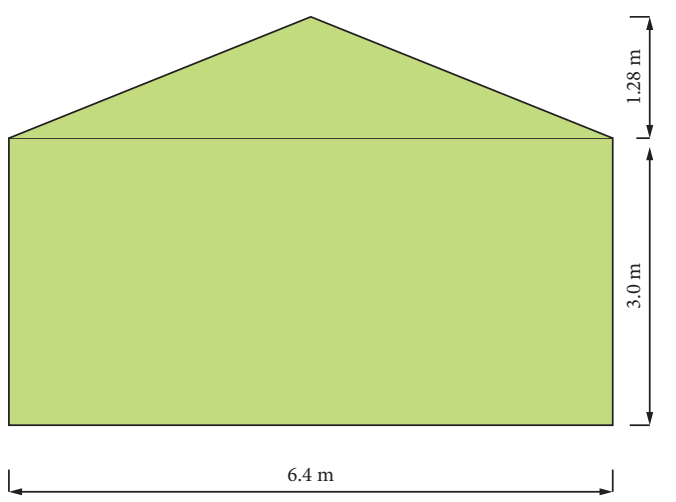

(c)

Figure 4: Dimensions and layout of the RACSR. (a) Plan view. (b) Front elevation. (c) Side elevation.

where $I_{1}$ is the invariant of the first principal stress, $J_{2}$ is the second deviatoric stress invariant, $\varphi$ is the internal friction angle of the soil, and $\theta_{\sigma}$ is the stress Rhode angle.

The yield surface of the Mohr-Coulomb yield condition is an irregular pyramid in three-dimensional stress space. The yield surface in the $\pi$-plane was a hexagon. The plastic potential function gives the direction of the next step of the plastic strain, whereas the yield function gives the magnitude of the next step of the plastic strain. When the Mohr-Coulomb yield criterion is adopted, the uncorrelated flow law is used. This model is suitable for soil materials with different tensile and compressive strengths.

In this report, the raw-soil structure of typical villages and towns in China was selected as the research object, and the soil wall was plain rammed earth. The main parameters are listed in Table 2 based on the tests performed and on [33]. LC3 soil has a density of $2150 \mathrm{~kg} / \mathrm{m}^{3}$, a Poisson's ratio of 0.30 , a cohesion of
$550 \mathrm{kPa}$, an internal friction angle of $50^{\circ}$, and an elastic modulus of $720 \mathrm{MPa}$. The colored-steel roof has a density of $10 \mathrm{~kg} / \mathrm{m}^{3}$, a Poisson's ratio of 0.25 , and an elastic modulus of 2-E8 MPa.

\section{Nonlinear Seismic Response Analysis of Raw-Soil Structures}

To obtain the dynamic characteristics of the RACSR structures, finite element models were established to calculate the vibration modes and natural frequencies of interest. A modal analysis was conducted using ABAQUS to obtain the fundamental modes of the RACSR models. The first three modal shapes are shown in Figure $7(\mathrm{a})$, and a summary of the frequency and modes that were utilized are listed in Table 3. Figure 7 indicates that the first two modes are translational motions, and the third mode is a twisting motion. 


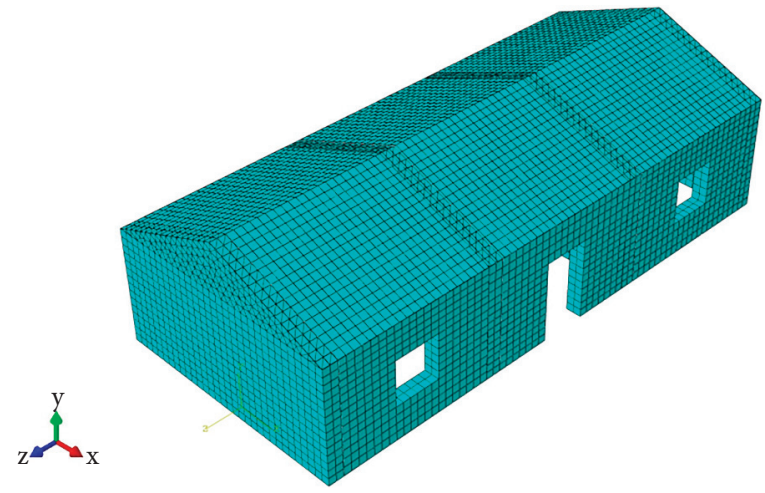

Figure 5: Finite element model and grid division of RACSR.

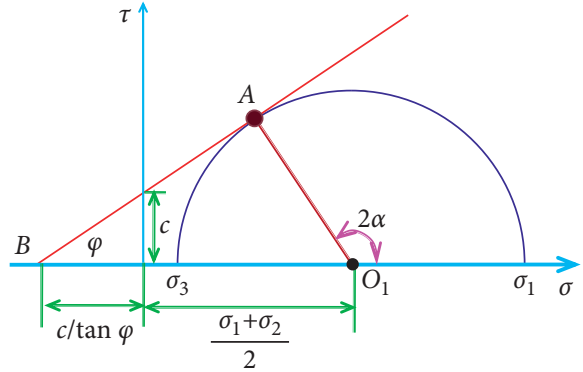

(a)

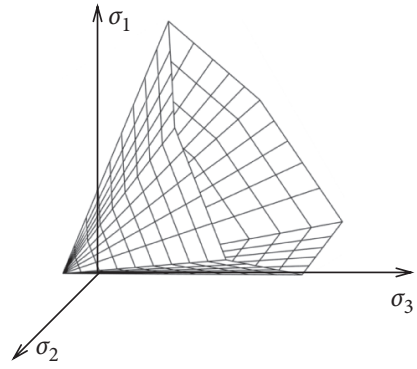

(b)

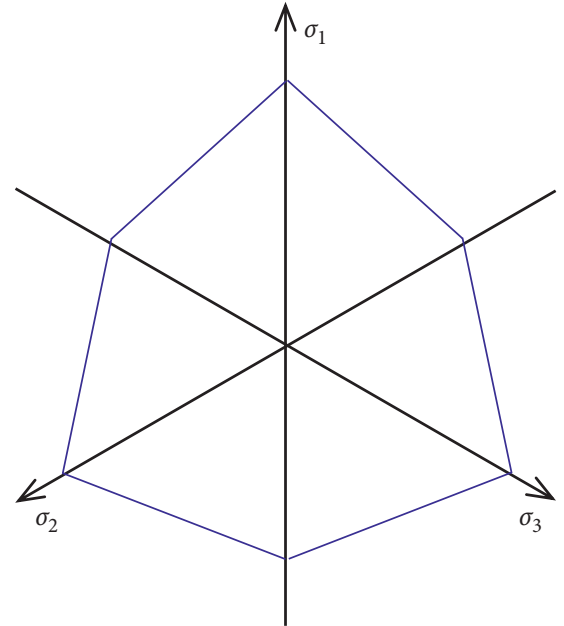

(c)

Figure 6: Mohr-Coulomb yield model. (a) Coulomb strength line and stress circle. (b) M-C yield surface in main stress space. (c) M-C yield curve on $\pi$-plane.

Given that ground motion is a very complex natural phenomenon, it has a high degree of uncertainty. Therefore, the selection of appropriate ground motion for dynamic time history analysis of a structure is necessary to achieve reliable calculated results. The specific earthquake types and classification criteria are presented in Table 4; the earthquakes were classified into five categories (SMSR, LMSR, SMLR, LMLR, and NEAR) according to the magnitude and epicentral distance. Referring to Zhang et al. [35] and using the magnitude-epicentral distance $(\mathrm{Mw}-\mathrm{R})$ band method, the ground motion was selected in a wide $\mathrm{Mw}-\mathrm{R}$ range considering the influence of near-fault ground motion on structural vulnerability. A total of 80 real ground motion records were selected from the strong ground motion database of the Pacific Earthquake Engineering Research Center (PEER). Figure 8 shows the $\mathrm{Mw}-\mathrm{R}$ distribution of the selected ground motion records from PEER. These records include all types of earthquakes, including 11 SMSR records, 10 SMLR records, 25 NEAR records, 22 LMSR records, and 12 LMLR records. Therefore, the uncertainty of the earthquake was considered in the simulation.
The 80 real ground motions were input to analyze the nonlinear seismic response of RACSR for different types of soil materials. The maximum interlayer displacement of raw-soil RACSR ranged from $2.3 \mathrm{~mm}$ to $72.4 \mathrm{~mm}$. Figure 9 shows a representative seismic wave (LMSR, G03-000, $\mathrm{PGA}=0.547 \mathrm{~g}$ ) and the corresponding roof displacement of the RACSR, where PGA denotes the peak ground acceleration. Figure 9(b) shows that the maximum displacement for the raw soil, modified soil, and LC3 soil and the positive and negative maximum values are $0.057,0.052$, and $0.046 \mathrm{~m}$ and $-0.0380,-0.0366$, and $-0.0362 \mathrm{~m}$, respectively. The corresponding displacement control ratios compared to the rawsoil RACSR were $8.77 \%, 19.29 \%, 3.68 \%$, and $4.74 \%$, respectively.

Table 5 lists 25 out of 80 maximum values of ISDA and the decreasing ratio (DR). ISDA-1, ISDA-2, and ISDA-3 are the interstory drift angle of raw-soil RACSR, modified soil RACSR, and LC3 soil RACSR, respectively. The DR is a ratio that describes the decreasing amplitude. DR- 1 and DR-2 are the decreasing amplitude ratios of ISDA-1 and ISDA-2, and ISDA-1 and ISDA-3, respectively. 
TABLE 2: Main physical properties of raw soil.

\begin{tabular}{lccccc}
\hline Soil type & Es $(\mathrm{MPa})$ & $\mu$ & $\mathrm{c}(\mathrm{kPa})$ & $\varphi\left({ }^{\circ}\right)$ & \\
\hline Raw soil [33] & 613 & 0.35 & 294 & 44 & 1950 \\
Modified soil [33] & 680 & 0.32 & 427 & 49 & 2100 \\
LC3 soil & 720 & 0.30 & 550 & 50 & 2150 \\
\hline
\end{tabular}

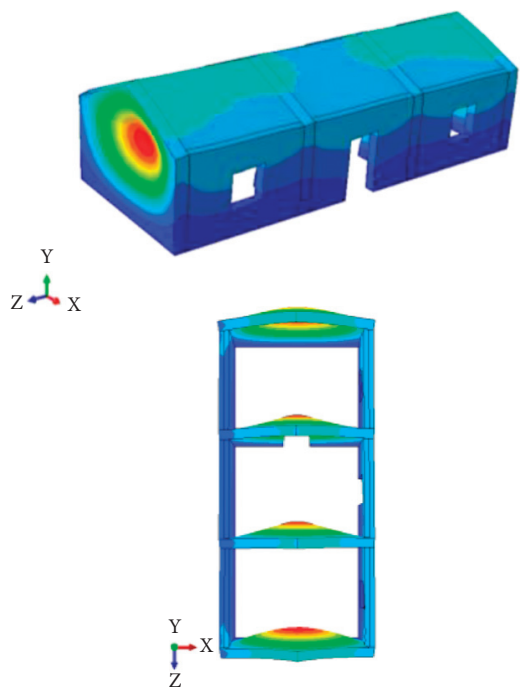

(a)

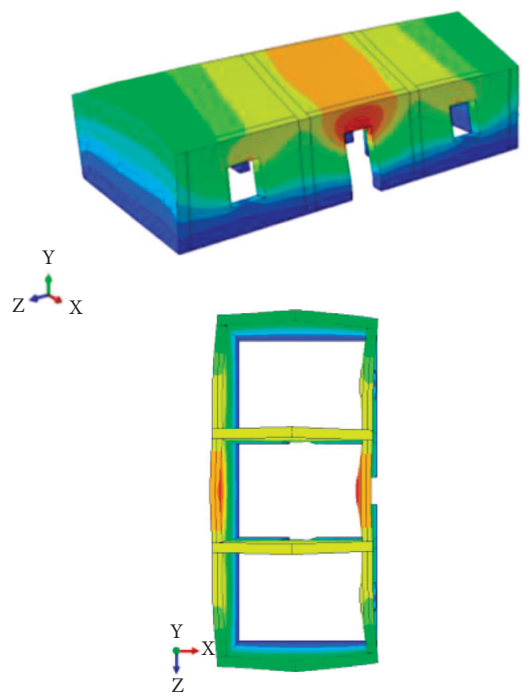

(b)

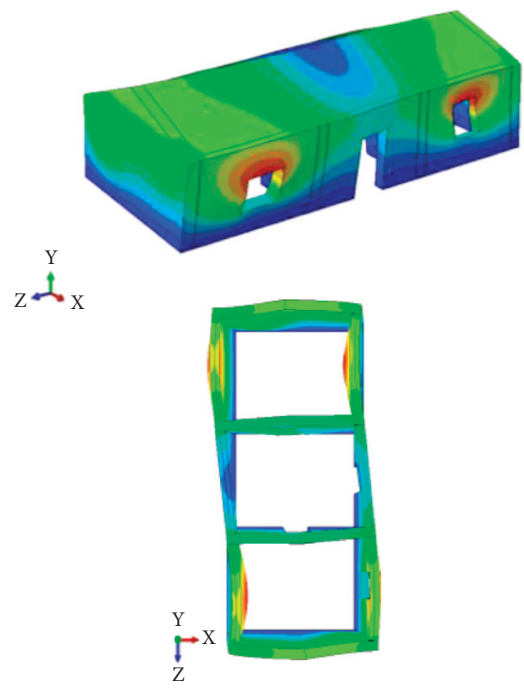

(c)

Figure 7: The first three modal shapes of the RACSR for the LC3 soil. Stereogram and plan view of (a) the first modal shape, (b) the second modal shape, and (c) the third modal shape.

TABLE 3: Frequencies of the first three modal shapes for three types of models.

\begin{tabular}{lccc}
\hline Model & RACSR with raw soil & RACSR with modified soil & RACSR with LC3 soil \\
\hline First modal shape & 12.365 & 12.443 & 12.592 \\
Second modal shape & 14.543 & 14.782 & 15.054 \\
Third modal shape & 17.545 & 17.755 & 18.033 \\
\hline
\end{tabular}

TABLE 4: Classification of earthquake types.

\begin{tabular}{llc}
\hline Group & Description & Data range \\
\hline SMSR & Small Mw, small $R$ & $5.8<\mathrm{Mw}<6.5,13 \mathrm{~km}<R<30 \mathrm{~km}$ \\
LMSR & Large Mw, small $R$ & $6.5<\mathrm{Mw}<7.0,13 \mathrm{~km}<R<30 \mathrm{~km}$ \\
SMLR & Small Mw, large $R$ & $5.8<\mathrm{Mw}<6.5,30 \mathrm{~km}<R<60 \mathrm{~km}$ \\
LMLR & Large Mw, large $R$ & $6.5<\mathrm{Mw}<7.0,30 \mathrm{~km}<R<60 \mathrm{~km}$ \\
NEAR & Near field seismic & Data of strong earthquake \\
\hline
\end{tabular}

As shown in Table 5, with the increase in the magnitude and PGA and the decrease in the epicentral distance, the maximum of the ISDA increases. When the magnitude and epicentral distances are different, the ISDA of the structure under the action of seismic waves with similar PGA is very close. For the same magnitude and different epicentral distances, the PGA increases in a stepwise manner, and the ISDA increases with the increase in the PGA. This shows that PGA is one of the main factors that affect the ISDA of rawsoil structure buildings. According to Figure 9(b), the displacement of the post-peak time shows that the global integrity of the stone-modified soil structure is different from that of the other two soils. For most seismic waves, the ISDA decreases from ISDA-1 to ISDA-3. This proves that the improvement and modification of raw soil can enhance the rigidity of the RACSR.

\section{Seismic Vulnerability Analysis of Raw-Soil Structures}

5.1. Probabilistic Seismic Demand Model. The probabilistic seismic demand (PSD) model characterizes the relationship between the engineering demand parameter (EDP) and ground motion intensity measure (IM). In the seismic vulnerability analysis of structures, the commonly used engineering demand parameters (EDPs) mainly include the 


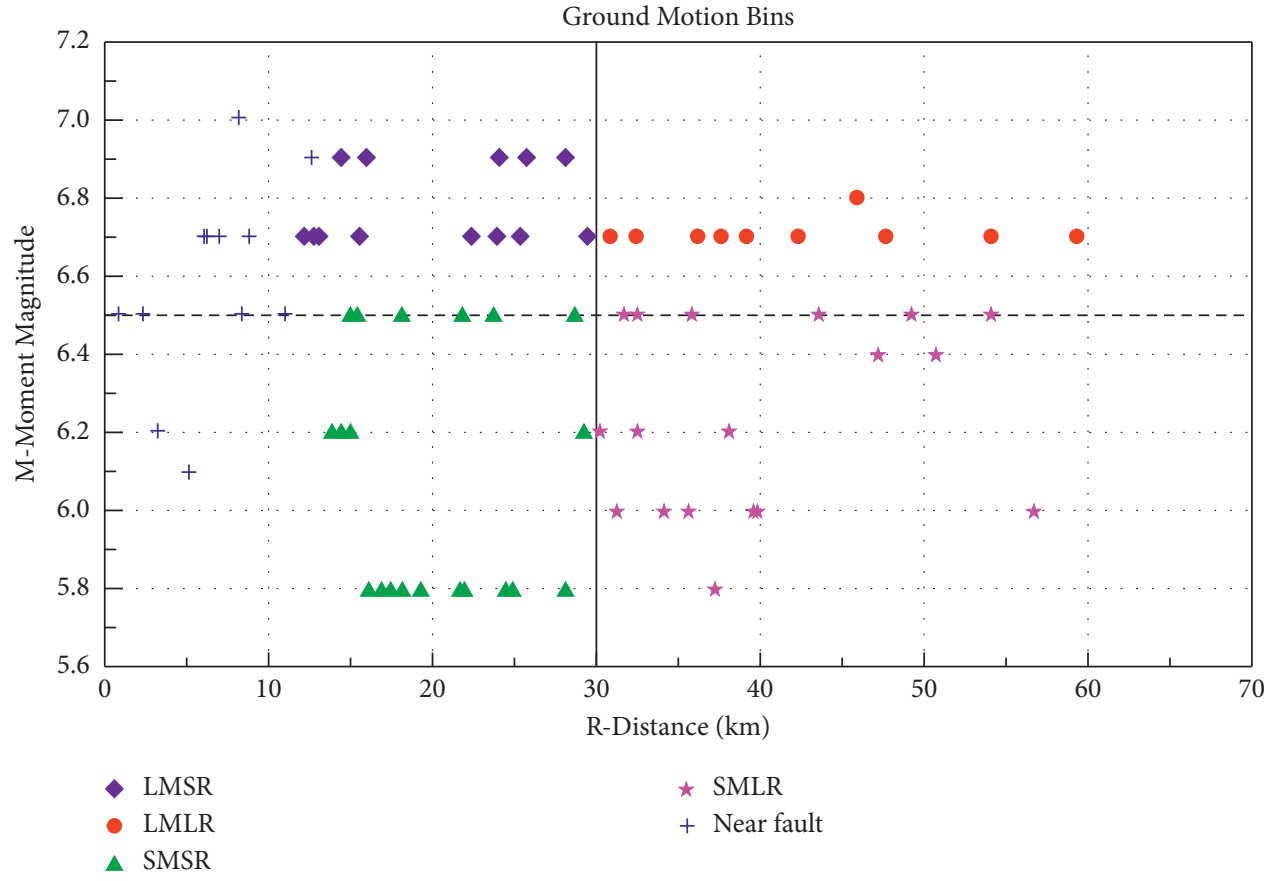

FIgURE 8: Mw-R distribution of 80 ground motion records.
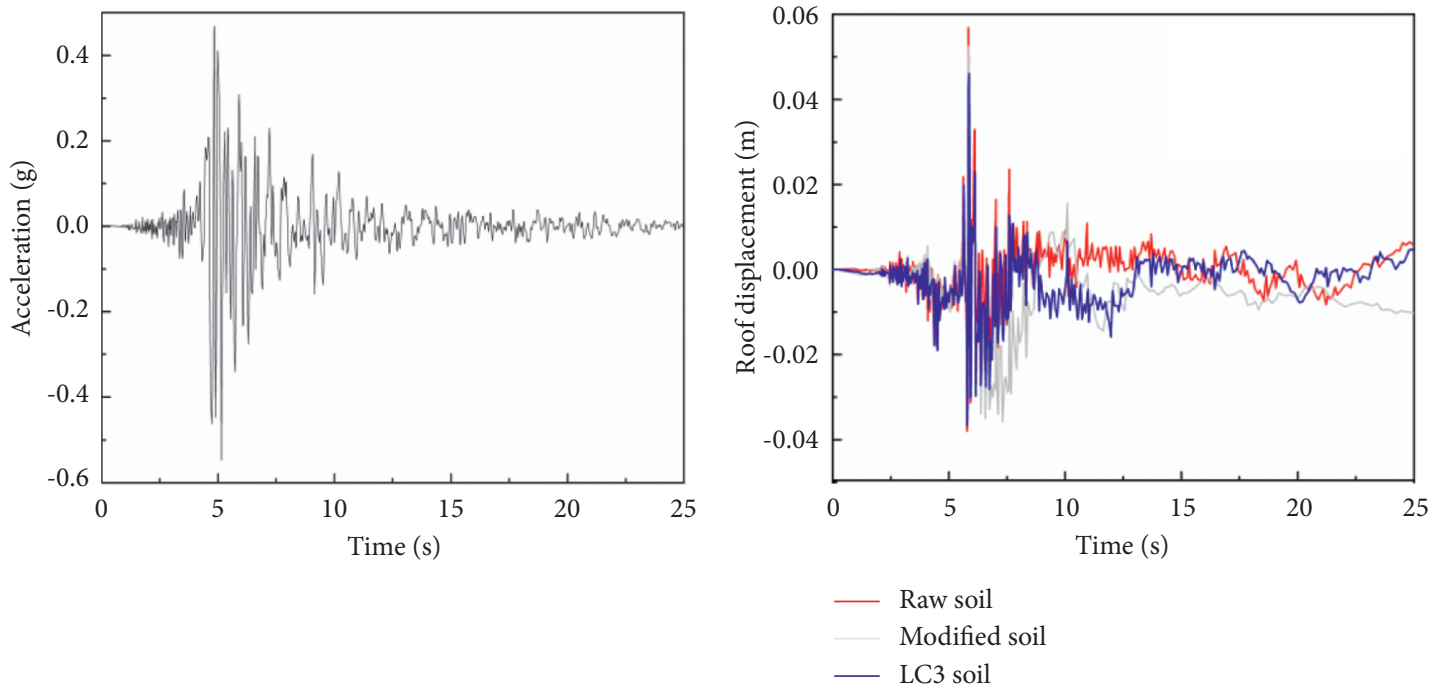

(a)

(b)

FIgure 9: A representative seismic wave (LMSR, G03-000, PGA = 0.547 g) and roof displacement of RACSR. (a) Acceleration time-history curves. (b) Roof displacement of RACSR.

top floor displacement, maximum value of ISDA, and the damage index. The ISDA is simple and intuitive in the analysis process and can better reflect the seismic demand of a structure. In the present study, the maximum ISDR and PGA were selected as the EDP and IM, respectively, for the PSD analysis of the three structures. Taking 80 real ground motions as the seismic excitation, the nonlinear dynamic time history analysis of RACSR was performed, and the corresponding relationship between seismic intensity parameters and the engineering demand parameters $\left(\mathrm{IM}_{i^{-}}\right.$
$\mathrm{EDP}_{i}$ ) under different conditions was obtained. Cornell et al. [36] proposed that the relationship between EDP and IM should satisfy the following logarithmic linear relation:

$$
\ln (\mathrm{EDP})=\ln a+b \ln (\mathrm{IM}) \text {. }
$$

The PSD model under each condition was obtained by fitting the results from the nonlinear dynamic time history analysis of the structure. The logarithmic standard deviation of the seismic demand can be expressed as follows: 
TABLE 5: Comparison of the maximum ISDA of RACSR under earthquake action.

\begin{tabular}{|c|c|c|c|c|c|c|c|}
\hline No & Earthquake motion & PGA (g) & ISDA-1 $\left(10^{-3}\right)$ & ISDA-2 $\left(10^{-3}\right)$ & ISDA-3 $\left(10^{-3}\right)$ & DR-1 (\%) & DR-2 (\%) \\
\hline 1 & A-CAS-000 & 0.332 & 0.009117 & 0.006085 & 0.005578 & 33.26 & 38.82 \\
\hline 2 & A-CAT-090 & 0.042 & 0.003741 & 0.001387 & 0.001389 & 62.92 & 62.87 \\
\hline 3 & BRA-315 & 0.16 & 0.005023 & 0.002804 & 0.003194 & 44.18 & 36.41 \\
\hline 4 & H-CHI-012 & 0.269 & 0.008223 & 0.008946 & 0.006655 & -8.79 & 19.07 \\
\hline 5 & M-G02-090 & 0.2 & 0.001442 & 0.00264 & 0.003633 & -83.08 & -151.94 \\
\hline 6 & A-BIR-180 & 0.299 & 0.00539 & 0.008729 & 0.002439 & -61.95 & 54.75 \\
\hline 7 & A-HAR-090 & 0.07 & 0.001999 & 0.001702 & 0.002676 & 14.86 & -33.87 \\
\hline 8 & H06-360 & 0.06 & 0.003779 & 0.000612 & 0.000331 & 83.81 & 91.24 \\
\hline 9 & H-CC4-045 & 0.115 & 0.000773 & 0.00073 & 0.001135 & 5.56 & -46.83 \\
\hline 10 & H-DLT-352 & 0.349 & 0.015638 & 0.002705 & 0.004238 & 82.70 & 72.90 \\
\hline 11 & G02-000 & 0.36 & 0.017496 & 0.008018 & 0.005291 & 54.17 & 69.76 \\
\hline 12 & GOF-090 & 0.283 & 0.0252 & 0.017947 & 0.006915 & 28.78 & 72.56 \\
\hline 13 & H-BCR-140 & 0.59 & 0.01696 & 0.002243 & 0.010584 & 86.77 & 37.59 \\
\hline 14 & H-E05-230 & 0.367 & 0.01021 & 0.011986 & 0.01157 & -17.39 & -13.32 \\
\hline 15 & NWH-360 & 0.59 & 0.007947 & 0.00604 & 0.002837 & 24.00 & 64.30 \\
\hline 16 & B-WSM-180 & 0.212 & 0.008989 & 0.006518 & 0.004895 & 27.49 & 45.54 \\
\hline 17 & CAP-090 & 0.395 & 0.010257 & 0.007827 & 0.002382 & 23.69 & 76.78 \\
\hline 18 & CNP-196 & 0.42 & 0.011264 & 0.016361 & 0.006297 & -45.25 & 44.10 \\
\hline 19 & FAR-090 & 0.243 & 0.012984 & 0.004981 & 0.003691 & 61.64 & 71.57 \\
\hline 20 & G03-000 & 0.547 & 0.01896 & 0.001919 & 0.010578 & 89.88 & 44.21 \\
\hline 21 & CEN-245 & 0.321 & 0.007043 & 0.006244 & 0.001594 & 11.34 & 77.37 \\
\hline 22 & LH1-090 & 0.077 & 0.00295 & 0.0005 & 0.000913 & 83.05 & 69.05 \\
\hline 23 & LV2-000 & 0.091 & 0.003645 & 0.007493 & 0.001686 & -105.57 & 53.74 \\
\hline 24 & PIC-180 & 0.18 & 0.011064 & 0.002823 & 0.003381 & 74.48 & 69.44 \\
\hline 25 & SOR-315 & 0.067 & 0.006688 & 0.001008 & 0.001766 & 84.93 & 73.59 \\
\hline
\end{tabular}

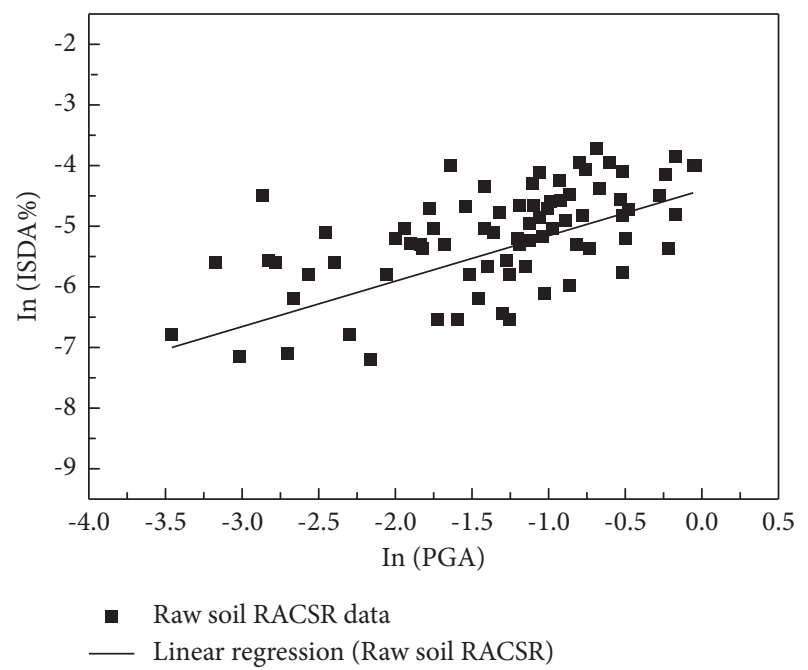

FIGURE 10: Probabilistic seismic demand model of raw-soil RACSR.

$$
\sigma_{D \mid \mathrm{IM}}=\sqrt{\frac{\sum_{i=1}^{N}\left[\ln \left(D_{i}\right)-\ln \left(a \mathrm{IM}_{i}^{b}\right)\right]^{2}}{N-2}},
$$

where $\sigma_{D \mid \mathrm{IM}}$ is the logarithmic standard deviation of earthquake demand, $N$ is the number of sample points in the regression analysis, $D_{i}$ is the peak value of the $i$ th seismic demand, $\mathrm{IM}_{i}$ is the PGA of the $i$ th ground motion, and $a$ and $b$ are the regression parameters.

Figures 10-12 show the PSD models of the RACSR under the action of a single main earthquake. Table 6 lists the mathematical expressions and related parameters of the PSD models under different conditions.

5.2. Vulnerability Analytical Method. The fragility function can be expressed as follows [37]:

$$
P(D \geq C \mid I M)=\Phi\left[\frac{\ln \left(\mu_{D}\right)-\ln \left(\mu_{C}\right)}{\sqrt{\sigma_{D \mid I M}^{2}+\sigma_{C}^{2}}}\right],
$$

where $D$ and $C$ are the seismic demand and structural capacity, respectively, IM is the ground motion intensity measure, $\mu_{D}$ and $\mu_{C}$ are the medians of $D$ and $C$, respectively, and $\sigma_{D \mid \mathrm{IM}}$ and $\sigma_{C}$ are the standard deviations corresponding to $D$ and $C$, respectively.

The national standard of the People's Republic of China (GB/T24335-2009) outlines a description of the degree of structural damage for five grades of soil and stone structure houses. The building damage was classified into five grades, as shown in Table 7.

The seismic vulnerability of a structure refers to the conditional probability that the structure reaches or exceeds a certain limit state under the action of earthquakes of different strengths; thus, it describes the probability distribution of all limit states of the structure. Therefore, the definition of the limit state is an important component of structural vulnerability analysis. The PGA was used as the IM and the ISDA was used as the EDP. According to the categorization of failure grade and performance level in Table 7, and referring to the ISDA limit values of each performance point for unreinforced clay brick walls in reference, four limit states of the raw-soil structure are 


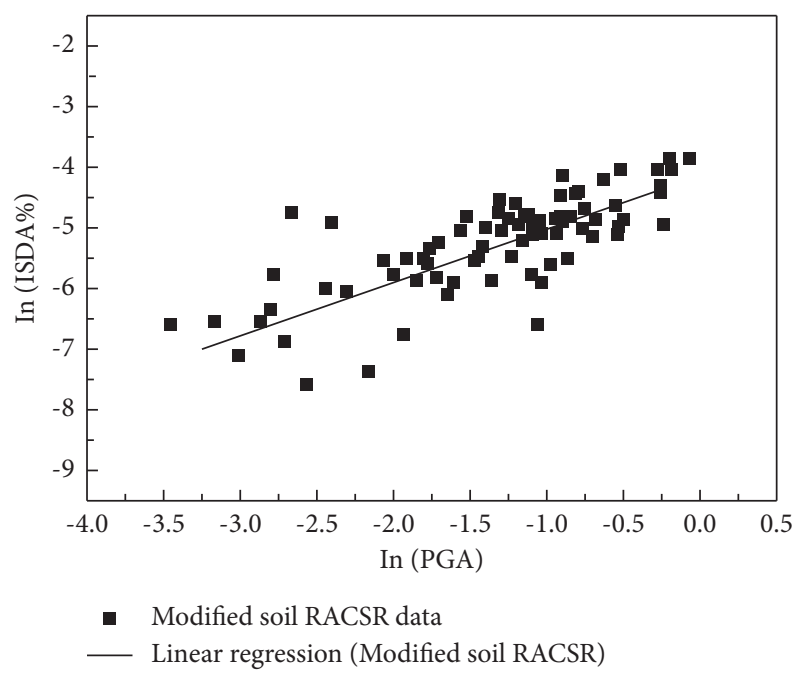

FIgURE 11: Probabilistic seismic demand model of modified soil RACSR.

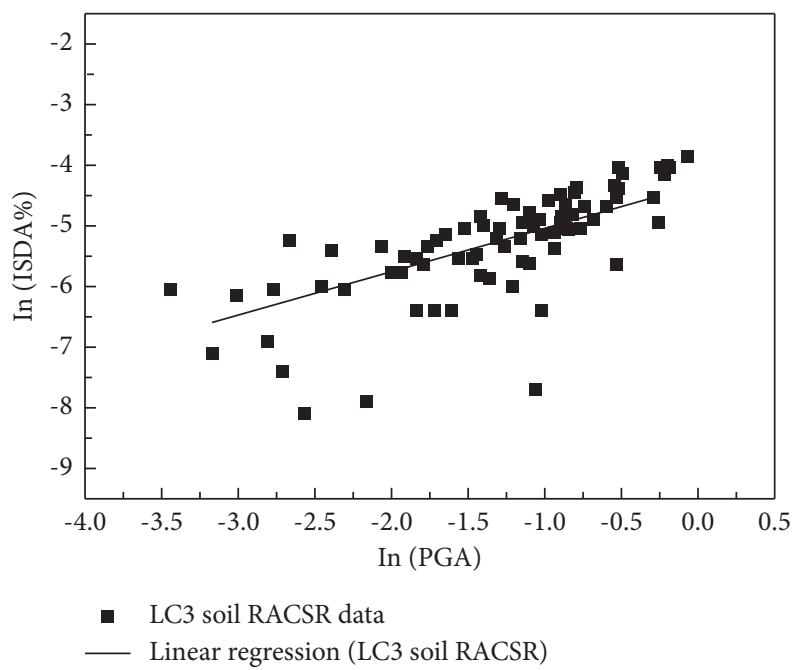

Figure 12: Probabilistic seismic demand model of LC3 soil RACSR.

TABLE 6: Parameters for the probabilistic demand models.

\begin{tabular}{llrr}
\hline Model & \multicolumn{1}{c}{ Regression model } & $R^{2}$ & $\sigma_{D \mid \mathrm{IM}}$ \\
\hline Raw soil & $\ln$ (ISDAmax) $=-4.34+0.619 \ln$ (PGA) & 0.628 & 0.15282 \\
Modified soil & $\ln$ (ISDAmax) $=-4.16+0.895 \ln$ (PGA) & 0.655 & 0.14733 \\
LC3 soil & $\ln$ (ISDAmax) $=-4.34+0.713 \ln$ (PGA) & 0.726 & 0.11074 \\
\hline
\end{tabular}

defined: slight damage (LS-1), moderate damage (LS-2), severe damage (LS-3), and collapse (LS-4). The ISDA corresponding to the four limit states is listed in Table 8. Under the limit state of slight damage (LS-1), it has a grade I intact state, and above the limit state of collapse (LS-4), it has a grade $\mathrm{V}$ collapsed state.

5.3. Vulnerability Results and Discussion. Figure 13 shows a comparison of the RACSR vulnerability curves for different limit states and earthquakes. The vulnerability curves of the raw-soil RACSR, modified soil RACSR, and LC3 soil RACSR model are presented for 80 real ground motions. The damage probability values of the raw-soil RACSR that was subjected to an earthquake were significantly higher than those of the modified soil RACSR and LC3 soil RACSR that were directly subjected to an earthquake of the same intensity.

As shown in Figure 13(a), considering the case of $\mathrm{PGA}=0.1 \mathrm{~g}$ as an example, the damage probabilities of rawsoil RACSR corresponding to the limit states of slight damage (LS-1), moderate damage (LS-2), severe damage (LS-3), and collapse (LS-4) are 99.19\%, 93.89\%, 77.37\%, and 
TABLE 7: Performance level and structural damage of masonry structure.

\begin{tabular}{|c|c|c|}
\hline $\begin{array}{l}\text { Damage } \\
\text { level }\end{array}$ & $\begin{array}{c}\text { Performance } \\
\text { level }\end{array}$ & Damage of structures and components \\
\hline I & Intact & $\begin{array}{l}\text { The main bearing walls are basically intact. The roof or vault is in good condition. Some non-load-bearing } \\
\text { components are slightly damaged, such as slight cracks in some doors and windows, sliding tiles on the } \\
\text { roof, etc. The structure functions normally and can be used without repair. }\end{array}$ \\
\hline II & Slight damage & $\begin{array}{l}\text { The bearing wall has no damage or some slight cracks in some cases. The roof and arch are basically intact. } \\
\text { Some non-load-bearing members have slight damage or some obvious damage, such as some non-load- } \\
\text { bearing walls have slight cracks, some have obvious cracks, the gable slightly flashes outside, the roof tiles } \\
\text { slide, etc. The basic function of the structure is not affected, and it can be used with little or no repair. }\end{array}$ \\
\hline III & $\begin{array}{l}\text { Moderate } \\
\text { damage }\end{array}$ & $\begin{array}{l}\text { Most of the load-bearing walls have slight cracks, some walls have obvious cracks, some walls have serious } \\
\text { cracks, and many cave arches have cracks. There are obvious cracks in some roofs and vaults. Some non- } \\
\text { load-bearing components have obvious damage, such as many parts of the wall plastering fall off, some } \\
\text { roof tiles fall off, etc. The basic function of the structure is affected to some extent, and it can be used after } \\
\text { repair. }\end{array}$ \\
\hline IV & Severe damage & $\begin{array}{l}\text { Most of the load-bearing walls have obvious cracks, and some of them have serious damage, such as wall } \\
\text { dislocation, breakage, internal or external tilt, or local collapse. Uplift or collapse of roof or vault, local } \\
\text { collapse, or the entire structure is obviously inclined. The basic function of the structure is seriously } \\
\text { affected, and even part of the function is lost, which is difficult to repair or has no repair value. }\end{array}$ \\
\hline V & Collapse & $\begin{array}{l}\text { Most of the walls are seriously broken or collapsed, and the roof or vault is seriously damaged and } \\
\text { collapsed. The structure is on the verge of collapse or completely collapsed. The function of the structure } \\
\text { no longer exists and there is no possibility of repair. }\end{array}$ \\
\hline
\end{tabular}

TABLe 8: Classification of damage limit states.

\begin{tabular}{lcccc}
\hline Damage limit states & LS-1 & LS-2 & LS-3 & \\
\hline ISDA & $1 / 1330$ & $1 / 800$ & $1 / 500$ & $1 / 330$ \\
\hline
\end{tabular}

$51.94 \%$, respectively. The damage probabilities of LC3 soil RACSR corresponding to the limit states of slight damage (LS-1), moderate damage (LS-2), severe damage (LS-3), and collapse (LS-4) are $95.22 \%, 79.1 \%, 50.72 \%$, and $24.76 \%$, respectively. At $\mathrm{PGA}=0.2 \mathrm{~g}$, the damage probabilities of raw-soil RACSR corresponding to the limit states of slight damage (LS-1), moderate damage (LS-2), severe damage (LS-3), and collapse (LS-4) were 99.91\%, 98.84\%, 93.32\%, and $78.06 \%$, respectively. The damage probabilities of LC3 soil RACSR corresponding to the limit states of slight damage (LS-1), moderate damage (LS-2), severe damage (LS-3), and collapse (LS-4) are 99.26\%, 94.31\%, 78.49\%, and $53.54 \%$, respectively. Thus, compared to the raw-soil RACSR model, the LC3 soil reduced the values of the damage limit states of LS-1, LS-2, LS-3, and LS-4 by factors of 1.04, 1.19, 1.53, and 2.1, respectively, for the same earthquake intensity. As shown in Figure 13(b), considering the case of $\mathrm{PGA}=0.1 \mathrm{~g}$ as an example, the damage probabilities of modified soil RACSR corresponding to the limit states of slight damage (LS-1), moderate damage (LS-2), severe damage (LS-3), and collapse (LS-4) are 93.67\%, 75.53\%, $46.73 \%$, and $22.19 \%$, respectively. At $\mathrm{PGA}=0.2 \mathrm{~g}$, the damage probabilities of the modified soil RACSR corresponding to the limit states of slight damage (LS-1), moderate damage (LS-2), severe damage (LS-3), and collapse (LS-4) are $99.58 \%, 96.42 \%, 84.80 \%$, and $63.47 \%$, respectively. That is, compared to the raw-soil RACSR model, the modified soil reduced the values of the damage limit states of LS-1, LS-2, LS-3, and LS-4 by factors of 1.01, 1.03, 1.11, and 1.23 , respectively, for the same earthquake intensity.

Figure 14 compares the fragility curves of the three models (raw-soil RACSR, modified soil RACSR, and LC3 soil RACSR) for different limit states (LS-1, LS-2, LS-3, and LS-4). As shown in Figure 14(a), taking PGA $=0.05 \mathrm{~g}$ as an example, the damage probability values of the slight damage limit state (LS-1) of the three models are $98.9 \%$, $81.8 \%$, and 89.2\%, respectively. As shown in Figure 14(b), taking $\mathrm{PGA}=0.1 \mathrm{~g}$ as an example, the damage probability values of the moderate damage limit state (LS-2) of the three models are $93.9 \%, 75.5 \%$, and $79.1 \%$, respectively. Figure $14(\mathrm{c})$ shows that taking $\mathrm{PGA}=0.1 \mathrm{~g}$ as an example, the damage probability values of the severe damage limit state (LS-3) of the three models are $77.4 \%, 46.7 \%$, and $50.7 \%$, respectively. When the $\mathrm{PGA}=0.2 \mathrm{~g}$, the three models are $93.0 \%, 84.8 \%$, and $78.5 \%$, respectively. Figure $14(\mathrm{~d})$ shows that taking $\mathrm{PGA}=0.1 \mathrm{~g}$, the damage probability values of the collapse limit state (LS-4) of the three models are $51.9 \%, 22.2 \%$, and $24.7 \%$, respectively. Taking PGA $=0.2 \mathrm{~g}$, the damage probability values of the collapse limit state (LS-4) of the three models are $78.1 \%$, $63.5 \%$, and $53.5 \%$, respectively. When $\mathrm{PGA}=0.4 \mathrm{~g}$, the damage probability values of the collapse limit state (LS4) of the three models are $93.6 \%, 93.3 \%$, and $83.7 \%$, respectively. 

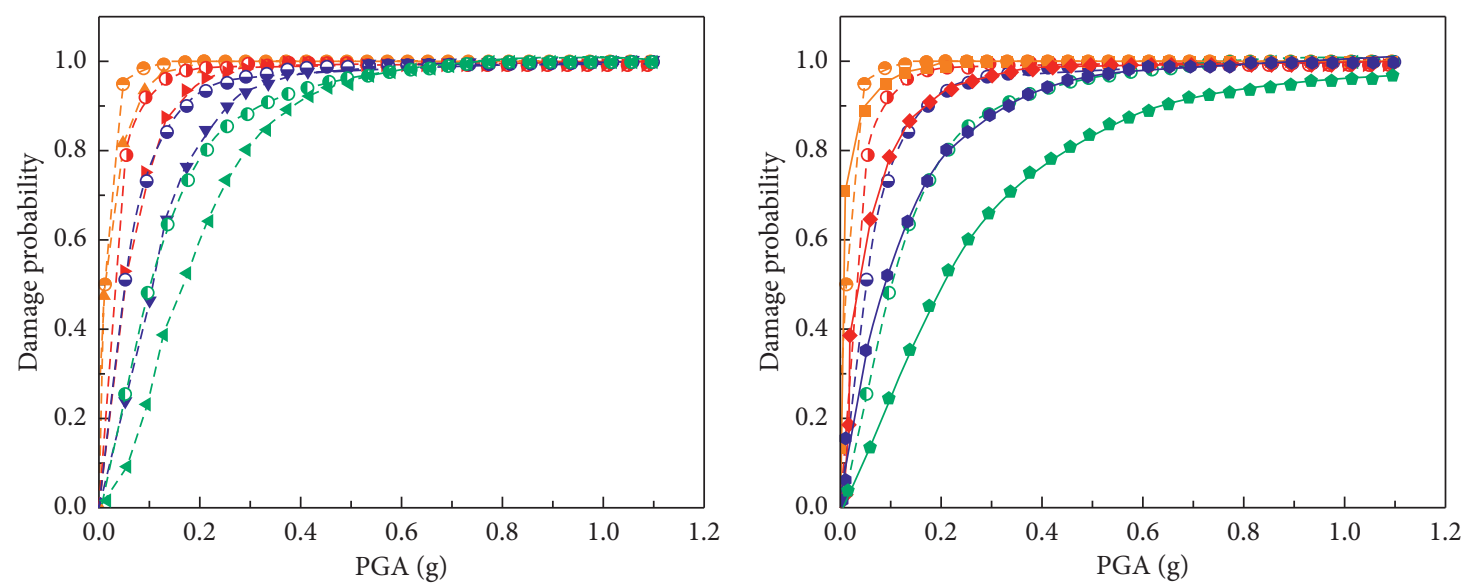

_ _- LS1-Modified soil RACSR

- - LS2-Modified soil RACSR

- - LS3-Modified soil RACSR

- 4 - LS4-Modified soil RACSR

- $\bullet$ - LS1-Raw soil RACSR

- - - LS2-Raw soil RACSR

- - - LS3-Raw soil RACSR

- - LS4-Raw soil RACSR

- $\bullet$ - LS1-Raw soil RACSR

- - - LS2-Raw soil RACSR

- - LS3-Raw soil RACSR

- o - LS4-Raw soil RACSR

-— LS1-LC3 soil RACSR

$\rightarrow \quad$ LS2-LC3 soil RACSR

- LS3-LC3 soil RACSR

- LS4-LC3 soil RACSR

(a)

(b)

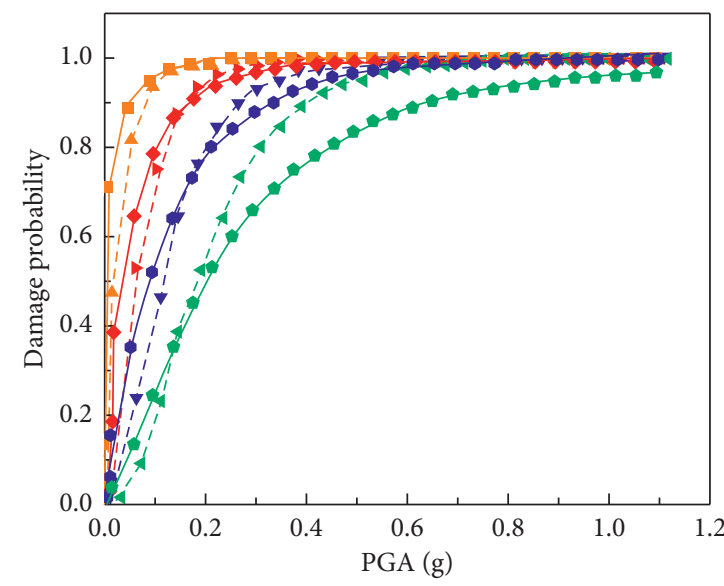

- _ - LS1-Modified soil RACSR

- - LS2-Modified soil RACSR

- - LS3-Modified soil RACSR

- 4- LS4-Modified soil RACSR

$\rightarrow$ LS1-LC3 soil RACSR

$\rightarrow-$ LS2-LC3 soil RACSR

$\rightarrow-$ LS3-LC3 soil RACSR

- LS4-LC3 soil RACSR

(c)

FIGURE 13: Comparison of vulnerability curves of RACSR under different materials. (a) Comparison of raw and LC3 soil. (b) Comparison of raw and modified soil. (c) Comparison of modified and LC3 soil. 

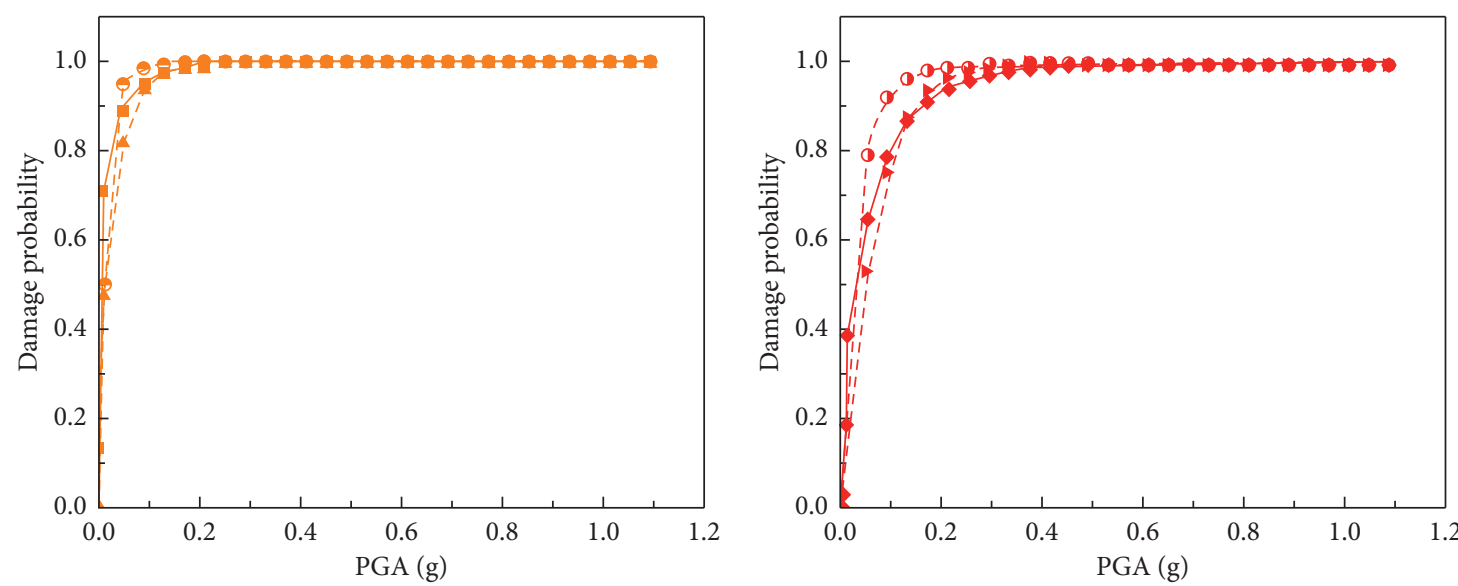

- - - LS1-Raw soil RACSR

- - LS1-Modified soil RACSR

$\rightarrow$ LS1-LC3 soil RACSR

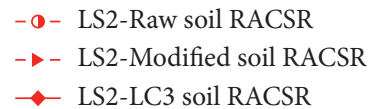

(b)

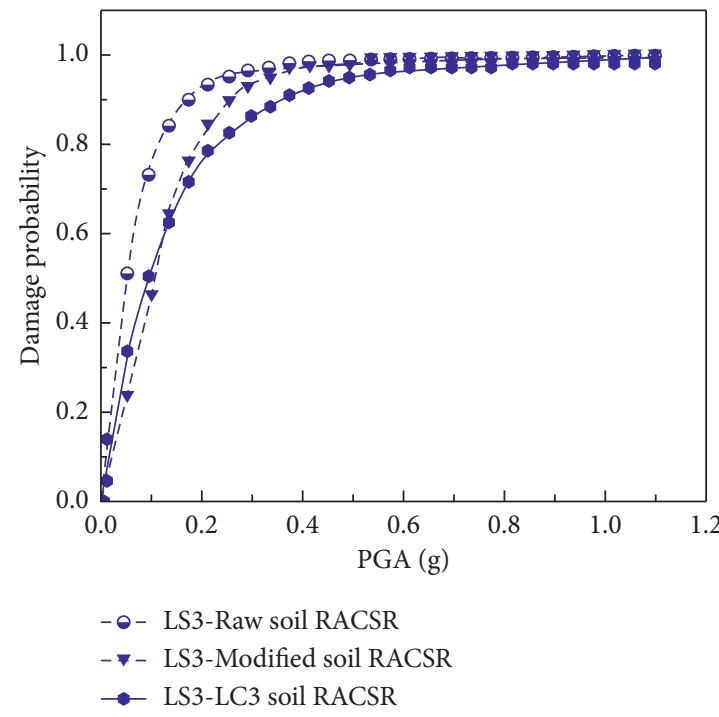

(c)

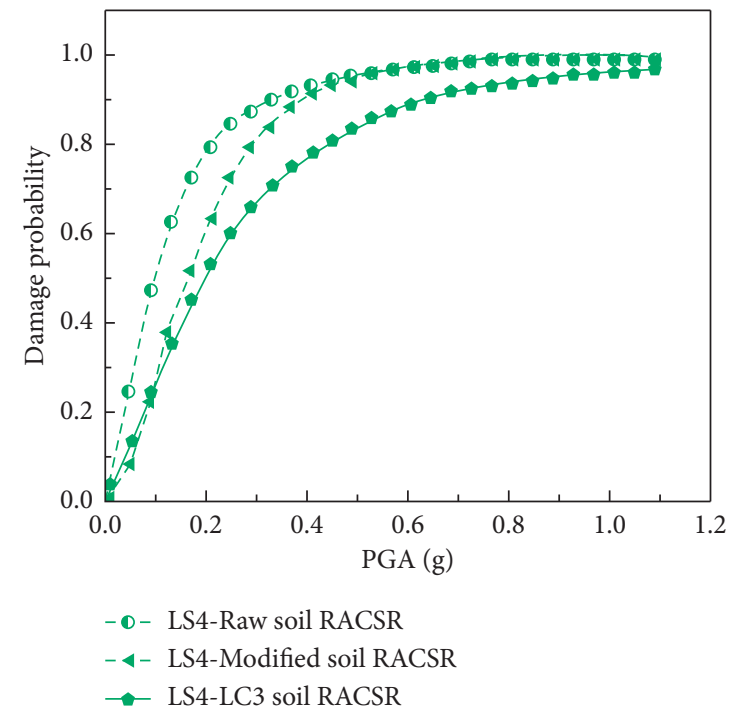

(d)

FIgURE 14: Comparison of vulnerability curves of RACSR under different limit states. (a) Comparison of LS-1. (b) Comparison of LS-2. (c) Comparison of LS-3. (d) Comparison of LS-4.

\section{Conclusion}

In this study, the seismic fragility of raw-soil structures that are representative of rural areas of China was investigated via numerical simulations. The effects of raw and modified soil on the fragility of rural structures were investigated in detail, considering the influence of LC3 soil. The main conclusions are as follows:

(1) Coal gangue-based LC3 was mixed with silicate cement clinker, coltan powder, limestone powder, and dehydrated gypsum in proportion $50: 30: 15: 5$. The LC3 soil strength with $5 \%$ or $10 \%$ cement can meet the demands of standard and engineering projects. The replacement of some cement clinker with coltan can significantly reduce the carbon footprint in cement production, and national policies of China encourage the reuse of solid waste. This type of modification material is effective, cheap, and environmentally friendly and can be used as a rural modification material

(2) Compared to the raw-soil RACSR model, the roof displacement and ISDA of the modified soil and LC3 soil RACSR models are both reduced to varying degrees, and the damage probability values for different damage limit states of the RACSR model are significantly lower. Therefore, it is necessary to improve the soil mechanics in rural raw-soil structures to enhance 
their structural integrity, reduce their seismic responses, and effectively mitigate the risk of severe structural damage or collapse

(3) For the seismic analysis of the raw-soil RACSR model, PGA is one of the main factors that influence the ISDA of raw-soil structure buildings. With the increase in magnitude and PGA and the decrease in the epicentral distance, the maximum value of the ISDA increased. When the magnitude and epicentral distance are different, the ISDA of the structure under the action of seismic waves with similar PGA is very close. The magnitude is the same, the epicentral distance is different, the PGA increases stepwise, and the ISDA increases with increasing PGA

(4) With an increase in the PGA, the damage probability value of each damage limit state of the structures increases. Taking PGA $=0.1 \mathrm{~g}$, the damage probabilities for raw-soil RACSR corresponding to the limit states of LS-1, LS-2, LS-3, and LS-4 are $99.19 \%, 93.89 \%, 77.37 \%$, and $51.94 \%$, respectively. At $\mathrm{PGA}=0.2 \mathrm{~g}$, the damage probabilities are 99.91\%, 98.84\%, 93.32\%, and 78.06\%. Compared to the raw-soil RACSR model, the modified soil and LC3 soil reduced the damage probability. For limit states of LS-1, LS-2, LS-3, and LS-4, the modified soil is reduced by factors of $1.01,1.03,1.11$, and 1.23 , respectively. The LC3 soil is reduced by factors of 1.04, 1.19, 1.53, and 2.1 , respectively, under the same earthquake intensity of $0.2 \mathrm{~g}$ as that of LS-1 to LS-4

(5) Relatively few modification methods were used in the study to improve the raw soil. The displacement of the post-peak time shows that the global integrity of the modified soil structure should be investigated in detail based on the soil failure mechanism. In addition, it is necessary to study the seismic performance and fragility of structures of various forms. This work serves as a theoretical reference for seismic design and performance improvement of raw-soil structures

\section{Data Availability}

The data that support the findings of this study are available from the corresponding author upon reasonable request.

\section{Conflicts of Interest}

The authors declare that there are no conflicts of interest regarding the publication of this study.

\section{Acknowledgments}

The authors are grateful for the financial support from the National Key R\&D Program of China (2018YFD1100402) and the Project of Liaoning Provincial Department of Science \& Technology (2020-BS-161).

\section{References}

[1] Y. H. Wang, J. Liang, X. Y. Zhang, Y. Zhang, and Y. Gao, "Review of raw-soil structure in China," Tu Mu Gong Cheng Xue Bao, vol. 48, no. 5, pp. 98-107, 2015.

[2] C. Jayasinghe, W. M. C. D. J. Fonseka, and Y. M. Abeygunawardhene, "Load bearing properties of composite masonry constructed with recycled building demolition waste and cement stabilized rammed earth," Construction and Building Materials, vol. 102, no. 1, pp. 471-477, 2016.

[3] L. Miccoli, U. Müller, and S. Pospíšil, "Rammed earth walls strengthened with polyester fabric strips: experimental analysis under in-plane cyclic loading," Construction and Building Materials, vol. 149, pp. 29-36, 2017.

[4] Y. B. Ma, N. Hushitaer, T. Akenjiang, and W. Naibi, "Experimental study on the mechanical properties of adobe masonry strengthened with ferrocement mortar," Earthquake resistant engineering and Retrofitting, vol. 40, no. 6, pp. 17-23, 2018.

[5] R. E. Klingner, W. M. McGinley, P. B. Shing, D. I. McLean, S. Jo, and H. Okail, "Seismic performance of low-rise woodframed and reinforced masonry buildings with clay masonry veneer," Journal of Structural Engineering, vol. 139, no. 8, pp. 1326-1339, 2013.

[6] G. S. Pavan, S. N. Ullas, and K. S. N. Rao, "Interfacial behavior of cement stabilized rammed earth: experimental and numerical study," Construction and Building Materials, vol. 257, Article ID 119327, 2020.

[7] T. Zhou, Z. Zhang, Z. Su, and P. Tian, "Seismic performance test of rammed earth wall with different structural columns," Advances in Structural Engineering, vol. 24, no. 1, pp. 107-118, 2021.

[8] Y. H. Bu, Y. H. Wang, and Y. Yin, "Study on seismic performance of raw-soil structure in China," Advanced Materials Research, vol. 250-253, no. 1-4, pp. 1862-1868, 2011.

[9] Q. B. Bui, S. Hans, J. C. Morel, and A. P. Do, "First exploratory study on dynamic characteristics of rammed earth buildings," Engineering Structures, vol. 33, no. 12, Article ID 3690369, 2011.

[10] Z. Li, M. Noori, and W. A. Altabey, "Experimental and numerical assessment on seismic performance of earth adobe walls," Structural Durability \& Health Monitoring, vol. 15, no. 2, pp. 103-123, 2021.

[11] H. Chen, Q. Xie, Z. Li, W. Xue, and K. Liu, "Seismic damage to structures in the 2015 Nepal earthquake sequences," Journal of Earthquake Engineering, vol. 21, no. 4, pp. 551-578, 2016.

[12] R. Illampas, D. C. Charmpis, and I. Ioannou, "Laboratory testing and finite element simulation of the structural response of an adobe masonry building under horizontal loading," Engineering Structures, vol. 80, no. 8, pp. 362-376, 2014.

[13] S. Ghasemalizadeh and V. Toufigh, "Durability of rammed earth materials," International Journal of Geomechanics, vol. 20, no. 11, Article ID 04020201, 2020.

[14] D. D. Tripura and K. D. Singh, "Mechanical behaviour of rammed earth column: a comparison between unreinforced, steel and bamboo reinforced columns," Materiales de Construcción, vol. 68, no. 332, Article ID 11517, 2018.

[15] D. D. Tripura, S. Gupta, B. Debbarma, and R. Satya, "Flexural strength and failure trend of bamboo and coir reinforced cement stabilized rammed earth wallettes," Construction and Building Materials, vol. 242, Article ID 117986, 2020. 
[16] J. W. An, G. Z. Nie, and B. Hu, "Area-wide estimation of seismic building structural types in rural areas by using decision tree and local knowledge in combination," International Journal of Disaster Risk Reduction, vol. 60, Article ID 102320, 2021.

[17] G. F. Zhao, Y. H. Ma, and X. F. Chen, "Analysis of seismic vulnerability of village buildings based on the standard of performance," China Civil Engineering Journal, vol. 47, no. 9, pp. 1-8, 2014.

[18] X. L. Li, Z. Q. Li, J. S. Yang et al., "Seismic vulnerability comparison between rural Weinan and other rural areas in western China," International Journal of Disaster Risk Reduction, vol. 48, Article ID 101576, 2020.

[19] J. H. He, W. Pan, J. Zhang et al., "Study on vulnerability of houses in rural areas of Yunnan province based on earthquake statistics since 1993," Building Structure, vol. 46, no. S1, pp. 379-383, 2016.

[20] B. T. Sun and G. X. Zhang, "Statistical analysis of seismic vulnerability of various building structures in Wenchuan earthquake," China Civil Engineering Journal, vol. 45, no. 5, pp. 26-30, 2012.

[21] Y. F. Ren, J. H. Yin, R. Z. Wen, and K. Ji, "The impact of ground motion inputs on the uncertainty of structural collapse fragility," Engineering Mechanics, vol. 37, no. 1, pp. 115-126, 2020.

[22] P. B. Lourenço and J. A. Roque, "Simplified indexes for the seismic vulnerability of ancient masonry buildings," Construction and Building Materials, vol. 20, no. 4, pp. 200-208, 2006.

[23] S. Lagomarsino and S. Giovinazzi, "Macroseismic and mechanical models for the vulnerability and damage assessment of current buildings," Bulletin of Earthquake Engineering, vol. 4, no. 4, pp. 415-443, 2006.

[24] L. Pasticier, C. Amadio, and M. Fragiacomo, "Non-linear seismic analysis and vulnerability evaluation of a masonry building by means of the SAP2000 V.10 code," Earthquake Engineering \& Structural Dynamics, vol. 37, no. 3, pp. 467485, 2008.

[25] A. Karbassi and M.-J. Nollet, "Performance-based seismic vulnerability evaluation of masonry buildings using applied element method in a nonlinear dynamic-based analytical procedure," Earthquake Spectra, vol. 29, no. 2, pp. 399-426, 2013.

[26] K. Byungmin and S. Moochul, "A model for estimating horizontal aftershock ground motions for active crustal region," Soil Dynamics and Earthquake Engineering, vol. 92, pp. 165-175, 2017.

[27] R. Giovanni and A. Claudio, "Effects of seismic sequences on masonry structure," Engineering Structures, vol. 166, pp. 227-239, 2018.

[28] G. L. Zhang, P. G. Wang, M. Zhao, X. Du, and X. Zhao, "Seismic structure-water-sediment-rock interaction model and its application to immersed tunnel analysis under obliquely incident earthquake," Tunnelling and Underground Space Technology, vol. 109, Article ID 103758, 2021.

[29] P. G. Wang, Y. D. Xu, X. L. Zhang, X. Renqiang, and X. Du, “A substructure method for seismic responses of offshore wind turbine considering nonlinear pile-soil dynamic interaction," Soil Dynamics and Earthquake Engineering, vol. 144, Article ID 106684, 2021.

[30] Y. T. Pang, X. Y. Zhou, W. He, J. Zhong, and O. Hui, "Uniform design-based Gaussian process regression for datadriven rapid fragility assessment of bridges," Journal of
Structural Engineering, vol. 147, no. 4, Article ID 04021008, 2021.

[31] Y. T. Pang and X. W. Wang, "Cloud-IDA-MSA conversion of fragility curves for efficient and high-fidelity resilience assessment," Journal of Structural Engineering, vol. 147, no. 5, Article ID 04021049, 2021.

[32] Y. Wang, "Study on modification of rammed earth material in mountain areas," Advanced Materials Research, vol. 261-263, pp. 1178-1181, 2011.

[33] D. G. Liu, Y. H. Xu, N. Wang, Y. Li, J. Lei, and R. Wang, "Compression test study on modification rammed earth with polypropylene fiber, gravel and geogrid," Building Structure, vol. 48, no. 14, pp. 108-123, 2018.

[34] A. Hasanbeigi, L. Price, H. Lu, and W. Lan, "Analysis of energy-efficiency opportunities for the cement industry in Shandong province, China: a case study of 16 cement plants," Energy, vol. 35, no. 8, pp. 3461-3473, 2010.

[35] H. Zhang, T. Sun, S. W. Hou, Q. M. Gao, and X. Li, "Effect of aftershocks on seismic fragilities of single-story masonry structures," Frontiers in Physics, vol. 9, Article ID 695111, 2021.

[36] C. A. Cornell, F. Jalayer, R. O. Hamburger, and D. A. Foutch, "Probabilistic basis for 2000 SAC federal emergency management agency steel moment frame guidelines," Journal of Structural Engineering, vol. 128, no. 4, pp. 526-533, 2002.

[37] C. Zhao, N. Yu, and T. Peng, "Vulnerability assessment of AP1000 NPP under mainshock-aftershock sequences," Engineering Structures, vol. 208, Article ID 110348, 2020. 